\title{
Genótipos de sorgo para produção de barra de cereais
}

\author{
Valéria Aparecida Vieira Queiroz ${ }^{(1)}$, Heliete Lopes Carneiro(1), Rosires Deliza(2), \\ José Avelino Santos Rodrigues(1), José Heitor de Vasconcellos ${ }^{(1)}$, Flávio Dessaune Tardin(1) \\ e Luciano Rodrigues Queiroz ${ }^{(1)}$
}

(1)Embrapa Milho e Sorgo, Rodovia MG-424, Km 65, CEP 35701-970 Sete Lagoas, MG. E-mail: valeria@cnpms.embrapa.br, helietecarneiro@yahoo.com.br, avelino@cnpms.embrapa.br, heitor@cnpms.embrapa.br, tardin@cnpms.embrapa.br, Irodqueiroz@yahoo.com.br (2)Embrapa Agroindústria de Alimentos, Avenida das Américas, № 29.501, Guaratiba, CEP 23020-470 Rio de Janeiro, RJ. E-mail: rodeliza@ctaa.embrapa.br

\begin{abstract}
Resumo - O objetivo deste trabalho foi desenvolver uma barra de cereais com pipoca de sorgo e avaliá-la quanto à aceitação do produto por consumidores, assim como identificar genótipos de sorgo e distintos modos de processamento para a produção de pipoca visando maior rendimento. Foram avaliados os processamentos sem (STH) e com tratamento hidrotérmico $(\mathrm{CTH})$ dos grãos antes do pipoqueamento. $\mathrm{O}$ tratamento $\mathrm{CTH}$ reduziu o percentual de piruás em cerca de $36 \%$ e aumentou o rendimento da produção de pipoca em cerca de $80 \%$. No STH, os genótipos BRS 310, BR 501, BR 506 e CMSXS 283 produziram menor percentual de piruás e maior capacidade de expansão. No CTH, 'BRS 310' e 'CMSXS 283' apresentaram melhor desempenho. Uma pesquisa sobre a aceitação e a intenção de compra das barras de cereais foi realizada em Londrina, PR e no Rio de Janeiro, RJ. Verificou-se que o produto foi aceito por 98,4 e 76,5\% dos consumidores, e a média de aceitação, em uma escala de 1 a 9, foi de 7,7 em Londrina e de 7,1 no Rio de Janeiro. Quanto à intenção de compra, verificou-se que $88,8 \%$ dos londrinenses e 80,6\% dos cariocas atribuíram notas acima de 4 ("talvez não comprasse, talvez comprasse") na escala de 7 pontos utilizada.
\end{abstract}

Termos para indexação: Sorghum bicolor, aceitação, análise sensorial, capacidade de expansão, consumidor.

\section{Sorghum genotypes for cereal bar production}

\begin{abstract}
The objective of this work was to develop a cereal bar with pop sorghum and evaluate it for consumer acceptance, as well as to identify sorghum genotypes and processing methods for pop sorghum production, in order to obtain a higher yield. Processing methods without $(\mathrm{STH})$ and with hydrothermal treatment $(\mathrm{CTH})$ of grains before expansion were evaluated. The CTH treatment reduced the percentage of nonexpanded grains in about $36 \%$ and increased pop sorghum yield in about $80 \%$. In the STH process, the genotypes BRS 310, BR 501, BR 506 and CMSXS 283 yielded the lowest percentage of nonexpanded grains and the greatest pop sorghum expansion capacity. In the CTH, 'BRS 310' and 'CMSXS 283' genotypes showed the best performance. A survey on acceptance and the purchasing intention was performed in Londrina, PR, and in Rio de Janeiro, RJ, Brazil. It was found that the cereal bar with pop sorghum was accepted by 98.4 and $76.5 \%$ of consumers, and the average scores, in a 1-9 scale, was 7.7 for Londrina and 7.1 for Rio de Janeiro. As for the purchasing intention, $88.8 \%$ of Londrina's testers and $80.6 \%$ of "Cariocas" attributed above-4 scores ("maybe do not buy, maybe buy") on the 7-point scale used.
\end{abstract}

Index terms: Sorghum bicolor, acceptance, sensorial analysis, expansion capacity, consumer.

\section{Introdução}

Com uma produção de mais de dois milhões de toneladas e rendimento médio de $2.580 \mathrm{~kg} \mathrm{ha}^{-1} \mathrm{o}$ sorgo foi o quarto cereal mais produzido no Brasil na safra 2010/2011, tendo perdido apenas para o milho, o arroz e o trigo (Companhia Nacional de Abastecimento, 2011). O sorgo tem a vantagem de ser mais eficiente no uso da água e de nutrientes do solo (Fialho et al., 2002) e tem menor custo de produção do que o milho, além de ser também comercializado por um valor mais baixo no mercado (Tsunechiro \& Miura, 2011).

Por sua versatilidade e facilidade de produção, estima-se que é utilizado como o alimento básico de mais de quinhentos milhões de pessoas que vivem em países em desenvolvimento, principalmente da África e da Ásia. Nesses países, o cereal chega a suprir 70\% da ingestão calórica diária, tendo, dessa forma, papel fundamental na segurança alimentar (Dicko et al., 2006; Mutisya et al., 2009).

No Brasil, assim como em muitos países, utiliza-se o sorgo basicamente na alimentação animal (Menezes et al., 2009; Pereira et al., 2009). No entanto, o interesse no uso desse cereal como alimento humano tem crescido em diversos países, em razão da presença de amido resistente, altos teores de fibra dietética e diversos compostos bioativos (Dykes et al., 2005; 
Rooney, 2007) que contribuem positivamente para a nutrição e a saúde humana. Na África, o sorgo em grão é utilizado no preparo de uma variedade de produtos alimentícios como mingau, cuscuz, produtos de panificação, cervejas e farinhas pré-cozidas para uso instantâneo (Acosta Sanches, 2003; Dicko et al., 2006; Méndez-Albores et al., 2009).

A composição química dos grãos de sorgo varia de acordo com o genótipo e, em todos eles, o amido corresponde ao principal macronutriente, com variação entre 55,6 e 75,2\% do cereal. Os teores de proteínas nos grãos variam entre 7,3 e 15,6\%, os de fibras entre 1,2 e $6,6 \%$, os de lipídeos entre 0,5 e $5,2 \%$, e os de cinzas entre 1,1 e 2,5\% (Waniska \& Rooney, 2000).

Schober et al. (2007) sugeriram que híbridos de sorgo, com características tecnológicas melhoradas para a elaboração de produtos alimentícios, podem ser identificados, e que programas de melhoramento podem selecionar cultivares que venham a contribuir para melhoria da produção de alimentos humanos. Perez González (2005) desenvolveu extrusados de excelente sabor, aparência e textura, a partir de grãos de pericarpo branco (sem tanino) e marrom (com tanino), integrais ou decorticados, e recomendou os produtos obtidos como excelente opção para a indústria alimentícia. Nesse mesmo trabalho, concluiu que o sorgo com tanino possibilitaria agregação de valor ao produto final, em virtude das propriedades antioxidantes do tanino. Além disso, sua aparência marrom-avermelhada poderia ser uma vantagem em produtos especiais, de coloração mais escura, sem a necessidade de adição de corantes artificiais, como é o caso dos cereais matinais com sabor e cor de chocolate.

Outra vantagem do uso do sorgo, na confecção de produtos alimentícios, é a possibilidade de utilização de grãos integrais. Recomenda-se atualmente o aumento do consumo de produtos derivados de grãos integrais, em razão de seu papel na redução do risco de doenças crônicas degenerativas. Vários estudos epidemiológicos têm mostrado que a ingestão de cereais integrais está associada à redução da incidência de diabetes, doenças cardiovasculares e determinados tipos de câncer (Pereira et al., 2002). Segundo Ragaee \& Abdel-Aal (2006), o desenvolvimento de novos produtos poderia auxiliar o aumento do consumo de cereais integrais, o que resultaria no aumento da ingestão de fibra e de outros componentes benéficos à saúde. Farelos de grãos ricos em fibras insolúveis têm sido utilizados na produção de barras de cereais, pães e cereais matinais, mas a palatabilidade deles tem limitado o nível de adição (Dutcosky et al., 2006).

Assim, com o intuito de estimular o consumo de sorgo no Brasil, iniciou-se, em 2007, uma linha de pesquisa que visa o desenvolvimento e a avaliação de produtos com sorgo integral, para uso na alimentação humana, entre os quais a barra de cereais com pipoca de sorgo, que é uma das formas de consumo dos grãos deste cereal. Elaborada a partir do grão integral, a pipoca de sorgo tem sabor agradável, semelhante ao da pipoca de milho, e já é utilizada em alguns países. Entretanto, deparou-se com a limitação no rendimento de sua produção, que é bastante baixo quando utilizado o método convencional, ou seja, quando se utiliza apenas o aquecimento dos grãos, o que torna inviável sua produção tanto para uso na forma de produto pronto para consumo, quanto para servir de ingrediente base na elaboração de outros produtos como, por exemplo, as referidas barras de cereais. Assim, foi necessário identificar os genótipos de sorgo, e elaborar o processo mais adequado para aumentar a capacidade de expansão dos grãos (CE), a fim de aumentar o rendimento e tornar viável a produção de pipoca de sorgo e de todos os produtos que a contenham na formulação.

A CE corresponde à relação entre o volume de pipoca e o volume ou o peso de grãos e é afetada, principalmente, pelo teor de água nos grãos, pelo grau de dano no pericarpo e no endosperma, e pelo método de secagem. No caso de grãos de milho, recomenda-se avaliar a CE quando os grãos contêm entre 13 e 14\% de umidade (Matta \& Viana, 2001; Santiago Luz et al., 2005).

O objetivo do presente trabalho foi desenvolver uma barra de cereais com pipoca de sorgo e avaliá-la quanto à aceitação por consumidores, assim como identificar genótipos de sorgo e distintos modos de processamento para a produção de pipoca de sorgo com maior rendimento em processamentos sem tratamento hidrotérmico (STH) e com tratamento hidrotérmico (CTH) dos grãos antes do pipoqueamento.

\section{Material e Métodos}

A barra de cereais com pipoca de sorgo foi desenvolvida pela Embrapa Milho e Sorgo, em Sete Lagoas, MG, e fabricada na planta piloto da Faculdade de Engenharia de Alimentos, do Centro Universitário de 
Belo Horizonte, MG, tendo-se utilizado os ingredientes e as respectivas proporções descritas na Tabela 1.

Nessa primeira etapa, a pipoca de sorgo foi preparada com grãos da cultivar BRS-309, desenvolvida pela Embrapa Milho e Sorgo safra 2007/2008, os quais se encontravam com o pericarpo e o gérmen íntegros e livres de impurezas. A expansão dos grãos foi obtida em pipoqueira elétrica, modelo h7340 (Proctor Silex, Grupo HB/PS, S.A. de C.V., Tlalnepantla, Estado de México, México). Para a preparação do xarope de aglutinação, foram aquecidos açúcar invertido, gordura hidrogenada, açúcar mascavo e lecitina, em panela de alumínio sob agitação, por cerca de um minuto. A gordura hidrogenada e a lecitina de soja foram pesadas em balança analítica, modelo BG 440 (Quimis Aparelhos Científicos, Diadema, SP, Brasil), e os açúcares invertido e mascavo em balança digital modelo BP15 2585/06 (Filizola, São Paulo, SP, Brasil). Os demais ingredientes (aveia, banana desidratada picada, pipoca de sorgo, flocos de arroz e canela em pó) foram adicionados ao xarope de aglutinação à temperatura de $95^{\circ} \mathrm{C}$, seguidos de enformagem e prensagem.

A partir do desenvolvimento da barra de cereais com pipoca de sorgo, foi possível constatar o baixo rendimento da pipoca, o qual apresentava grande variação conforme o genótipo e o método de preparo utilizados. Assim, para a validação do processo de produção da barra de cereais com pipoca de sorgo, foi necessária uma segunda etapa para avaliar os genótipos de sorgo e as formas de processamento que favorecessem maior rendimento do processo, ou seja, menor quantidade de piruás (grãos não expandidos, característica indesejável) e maior capacidade de expansão dos grãos (característica desejável).

Tabela 1. Ingredientes e proporções (\%) utilizadas na elaboração da barra de cereais com pipoca de sorgo.

\begin{tabular}{lc}
\hline Ingrediente & Quantidade (\%) \\
\hline Aveia & 23,1 \\
Banana desidratada & 23,1 \\
Açúcar invertido & 23,0 \\
Açúcar mascavo & 14,4 \\
Pipoca de sorgo BRS 309 & 7,2 \\
Flocos de arroz & 5,8 \\
Gordura vegetal hidrogenada & 1,7 \\
Lecitina de soja & 1,4 \\
Canela em pó & 0,3 \\
\hline
\end{tabular}

Foram utilizados oito genótipos - BR 007B, BRS 305, BRS 309, BRS 310, BR 501, BR 506, BR 700 e CMSXS 283 - todos cultivados e colhidos nas mesmas condições, nos campos experimentais da Embrapa Milho e Sorgo, safra 2007/2008.

A fim de homogeneizar os lotes amostrais, o teor de água dos grãos de todas as cultivares foi corrigido para $13 \%$, após resultados obtidos em teste preliminar com o genótipo BRS 310 (Tabela 2) e conforme os resultados apresentados por Santiago Luz et al. (2005) como o teor mais adequado para a produção de pipoca de milho.

Foram utilizados $80 \mathrm{~mL}$ de grãos de cada genótipo, medidos em proveta de $500 \mathrm{~mL}$ e testados em dois modos de processamento, antes da expansão dos grãos: processo sem tratamento hidrotérmico (STH) e processo com tratamento hidrotérmico $(\mathrm{CTH})$. Para isso, os grãos foram transferidos para uma peneira e lavados em água potável corrente, por cerca de $2 \mathrm{~min}$, acondicionados em recipiente e, em seguida, foi adicionada água na proporção $1: 1(\mathrm{p} / \mathrm{v}) \mathrm{e}$, finalmente, os grãos foram aquecidos a aproximadamente $200^{\circ} \mathrm{C}$, mexidos continuamente até que toda a água adicionada evaporasse, e os grãos permanecessem ainda úmidos. Os grãos - todo o volume de $80 \mathrm{~mL}$ - de ambas as formas de processamento, seguindo-se ordem aleatória obtida por meio de sorteio, foram submetidos ao pipoqueamento na pipoqueira elétrica anteriormente citada. A pipoqueira foi pré-aquecida por $5 \mathrm{~min}$, antes do início dos experimentos, para evitar diferenças entre os tratamentos. Depois da expansão dos grãos, o volume de pipoca obtido foi medido em proveta de $1.000 \mathrm{~mL}$, e o volume e a massa dos piruás em proveta de $100 \mathrm{~mL}$ e em balança analítica, respectivamente.

Pesaram-se os $80 \mathrm{~mL}$ de grãos de cada genótipo, em balança com duas casas decimais, para obtenção da massa dos grãos (g). As características avaliadas foram: percentagem de piruás (PP), obtida pela massa dos

Tabela 2. Capacidade de expansão de grãos de sorgo do genótipo BRS 310, com teores de água entre 10 e $14 \%$.

\begin{tabular}{lc}
\hline Teor de água dos grãos (\%) & Capacidade de expansão \\
\hline 10 & $261,7 \mathrm{c}$ \\
11 & $426,7 \mathrm{~b}$ \\
12 & $534,2 \mathrm{a}$ \\
13 & $531,7 \mathrm{a}$ \\
14 & $561,7 \mathrm{a}$ \\
\hline \multicolumn{2}{c}{ Médias seguidas de letras iguais minúsculas, na coluna, não diferem entre } \\
si, pelo teste de Tukey, a 5\% de probabilidade.
\end{tabular}


piruás (g) em $100 \mathrm{~g}$ de grãos, antes do pipoqueamento, e a capacidade de expansão (CE), obtida pela razão entre o peso $(\mathrm{g})$ de $80 \mathrm{~mL}$ de grãos medidos e os grãos pesados antes do pipoqueamento (Granate et al., 2002).

Utilizou-se o delineamento experimental inteiramente casualizado, em arranjo fatorial 8x2 (8 genótipos x 2 tipos de processamento), com três repetições. Os dados obtidos foram avaliados por análise de variância (ANOVA). As interações significativas foram desdobradas, e as médias dos tratamentos foram comparadas pelo teste de Duncan a 1 ou a $5 \%$ de probabilidade. Utilizou-se o programa estatístico Genes (Cruz, 1997).

Após o desenvolvimento da barra de cereais com pipoca de sorgo e a avaliação dos genótipos e processos, para a produção de pipoca de sorgo, foi realizada uma terceira etapa do trabalho, para avaliar a aceitação e a intenção de compra pelos consumidores. Para tanto, foram produzidas unidades de barras de cereais na empresa Tia Mona, em Nova Lima, MG, tendose utilizado os mesmos ingredientes e proporções descritas na Tabela 1, com alteração apenas para 0 genótipo de sorgo. Utilizou-se a cultivar BRS 310, que apresentou o melhor desempenho quanto à produção de pipoca no estudo com os oito genótipos. Após a prensagem em assadeiras de alumínio, a massa foi cortada em retângulos semelhantes aos das barras de cereais comerciais, os quais foram acondicionados, individualmente, em embalagens de filme flexível $\mathrm{PET} / \mathrm{PEBD} / \mathrm{AL}$ - politereftalato de etileno, polietileno de baixa densidade e película de folha de alumínio cedidas pela empresa Tia Mona. O produto embalado ficou armazenado em caixas de papelão, à temperatura ambiente, durante cinco dias até a data de análise.

A avaliação de aceitação e de intenção de compra da barra de cereais com pipoca de sorgo foi realizada em dois locais distintos: Londrina, PR, e Rio de Janeiro, RJ. Em Londrina (T1), o teste foi realizado durante o XXVII Congresso Nacional de Milho e Sorgo, no salão de refeições, com 125 participantes de ambos os sexos, que foram convidados a acomodar-se em mesinhas com quatro lugares e instruídos a não se comunicar uns com os outros durante o preenchimento dos questionários. No Rio de Janeiro (T2), o teste foi realizado em cabines individuais, do Laboratório de Análise Sensorial da Embrapa Agroindústria de Alimentos, com a participação de 98 consumidores, recrutados entre estagiários e funcionários dessa instituição. Em ambos os locais, solicitou-se ao avaliador que marcasse, em folha apropriada, a resposta que melhor refletisse seu julgamento em relação à aceitação e à intenção de compra do produto. Não foi revelado que a barra de cereais continha sorgo na formulação.

A aceitação do produto foi avaliada por meio de escala hedônica estruturada de nove pontos, que variou de "desgostei extremamente" (nota 1) a "gostei extremamente" (nota 9). Amostras correspondentes à metade de uma barra de cereal foram servidas a cada consumidor, em pratos descartáveis de plástico. A intenção de compra foi avaliada em escala de 7 pontos e variou de "certamente não compraria" (nota 1) a "certamente compraria" (nota 7). A nota 5 ("não gostei/nem desgostei"), da escala hedônica de 9 pontos, referiu-se ao valor limite da aceitação da barra de cereais, pois abaixo dele estavam todos os termos relacionados a "desgostei" (Queiroz et al., 2007). Assim, foram consideradas aceitas as amostras que receberam, em média, nota superior a 5.

Os dados do teste de aceitação foram analisados por análise da distribuição de frequência, pelo programa Excel.

\section{Resultados e Discussão}

Houve diferença significativa $(\mathrm{p}<0,01)$ quanto à percentagem de piruás (PP) entre os genótipos e entre os modos de processamento, mas não houve diferença na interação genótipos $\mathrm{x}$ tipo de processamento; assim, avaliaram-se isoladamente as médias dos dois fatores estudados. Considerando-se que, para pipoca, o desejável é que se obtenha o menor número de piruás após o pipoqueamento, observou-se que o processo CTH foi $36 \%$ mais eficiente na conversão de grãos em pipoca do que o processo STH (Tabela 3). Os genótipos BRS 310, BR 501, BR 506 e CMSXS 283 apresentaram melhor desempenho quanto a essa variável.

Quanto à capacidade de expansão (CE), verificouse diferença significativa $(p<0,01)$ tanto entre os genótipos, e entre os tipos de processamento, como na interação entre eles. Assim, as médias dos genótipos foram comparadas dentro de cada processo, e as médias de cada processo foram comparadas dentro de cada genótipo (Tabela 3). A média da CE foi $1,8 \mathrm{vez}$ maior no CTH do que no STH. Yenagi et al. (2005) avaliaram 101 cultivares nativas de sorgo, pelo método 
STH para a produção de pipoca, e também encontraram variabilidade genética quanto à capacidade de expansão entre 4,14 e 11,96 $\mathrm{mL} \mathrm{g}^{-1}$, resultados intermediários aos do presente trabalho, nos dois processos aplicados. Da mesma forma, Gundboudi (2006) obteve CE entre 12,33 e $16,33 \mathrm{~mL} \mathrm{~g}^{-1}$ (STH), em seis cultivares de sorgo cultivadas em duas épocas diferentes, com resultados semelhantes aos obtidos com a aplicação do CTH. Os resultados indicam que é possível alcançar um rendimento ainda maior do que o obtido no presente trabalho, se for intensificada a busca por genótipos mais propícios à produção de pipoca aliada ao emprego do tratamento hidrotérmico anterior ao pipoqueamento dos grãos.

Verificou-se que, em todos os genótipos avaliados, a $\mathrm{CE}$ dos grãos foi maior com a aplicação do tratamento hidrotérmico dos grãos antes do pipoqueamento, que foi capaz de elevar o rendimento de pipoca em cerca de $80 \%$ em relação ao processo STH. Esse fato pode ser explicado pelo aumento do teor de água no interior dos grãos, proporcionado pelo tratamento hidrotérmico. De acordo com Santiago Luz et al. (2005), a umidade da semente é um dos fatores mais importantes na capacidade de expansão dos grãos de milho.

Os genótipos BRS 310, BR 501, BR 506 e CMSXS 283 apresentaram os melhores índices de CE dentro do processo STH, com valores mais de três vezes maiores do que com o genótipo BR 007. No processo CTH, o genótipo BRS 310 destacou-se dos demais, e o genótipo CMSXS 283 apresentou o segundo maior valor. Confirmando o que já era esperado, os melhores genótipos quanto à capacidade de expansão foram os mesmos que apresentaram menor percentual de piruás.

Os resultados da avaliação de aceitação e de intenção de compras mostraram que, em relação às características que mais agradaram aos consumidores da barra de cereais com pipoca de sorgo, $57 \%$ de Londrina e $43 \%$ do Rio de Janeiro citaram primeiramente o sabor, seguido de textura, aparência e aroma. Quanto às características de que os consumidores menos gostaram, as respostas nos dois locais foram bastante diversas; porém, mais de $60 \%$ dos avaliadores do Rio de Janeiro e $40 \%$ de Londrina responderam que nada os desgostou. Os demais consumidores citaram os atributos "consistência", "pegajoso nos dentes", "seco" e "textura elástica".

Os resultados da aceitação e intenção de compra das barras de cereais com pipoca de sorgo estão apresentados na Figura 1. Para notas acima de 5, em que se considerou oproduto como "aceito pelo consumidor", verifica-se que, em Londrina e no Rio de Janeiro, o produto foi aceito por 98,4 e $76,5 \%$ dos participantes, respectivamente. Varias razões afetam a preferência do consumidor e podem, portanto, explicar a diferença em relação aos resultados obtidos nas duas cidades, pois, apesar de não ter sido revelado previamente aos avaliadores a composição da barra de cereais em estudo, é comum associar-se o consumo desse tipo de produto com hábito saudável de alimentação (Freitas \& Moretti, 2006). Fatores como atitude em relação à saúde, ao meio ambiente,

Tabela 3. Percentagem de piruás (PP) e capacidade de expansão (CE) de pipoca, em oito genótipos de sorgo, obtidas de grãos sem tratamento hidrotérmico (STH) e com tratamento hidrotérmico $(\mathrm{CTH})$, antes do pipoqueamento.

\begin{tabular}{|c|c|c|c|c|c|c|}
\hline \multirow[t]{2}{*}{ Genótipo } & \multicolumn{3}{|c|}{$\mathrm{PP}^{(1)}(\%)$} & \multicolumn{3}{|c|}{$\mathrm{CE}^{(2)}\left(\mathrm{mL} \mathrm{g}^{-1}\right)$} \\
\hline & STH & $\mathrm{CTH}$ & Média & STH & CTH & Média \\
\hline BR $007 \mathrm{~B}$ & 51,68 & 36,84 & $44,26 a$ & $2,97 \mathrm{bB}$ & $6,24 \mathrm{dA}$ & 4,60 \\
\hline BRS 305 & 48,31 & 34,00 & $41,15 \mathrm{a}$ & $4,31 \mathrm{bB}$ & 7,79dA & 6,05 \\
\hline BRS 309 & 43,53 & 39,27 & $41,40 \mathrm{a}$ & $4,57 \mathrm{bB}$ & $6,51 \mathrm{dA}$ & 5,54 \\
\hline BRS 310 & 37,57 & 11,06 & $24,31 b$ & $6,20 \mathrm{aB}$ & $16,78 \mathrm{aA}$ & 11,49 \\
\hline BR 501 & 17,52 & 26,29 & $21,91 b$ & $9,31 \mathrm{aB}$ & $12,20 \mathrm{cA}$ & 10,75 \\
\hline BR 506 & 35,36 & 25,14 & $30,25 \mathrm{ab}$ & $7,24 \mathrm{aB}$ & $12,24 \mathrm{cA}$ & 9,74 \\
\hline BR 700 & 47,97 & 36,62 & $42,30 \mathrm{a}$ & $4,03 \mathrm{bB}$ & $7,47 \mathrm{dA}$ & 5,75 \\
\hline CMSXS 283 & 25,35 & 15,89 & $20,62 b$ & $6,90 \mathrm{aB}$ & $12,99 \mathrm{bA}$ & 9,94 \\
\hline Média & $38,41 \mathrm{~A}$ & $28,14 \mathrm{~B}$ & - & 5,69 & 10,28 & - \\
\hline
\end{tabular}

${ }^{(1)}$ Médias para PP, seguidas de letras iguais, minúsculas nas colunas e maiúsculas nas linhas , não diferem entre si, pelo teste de Duncan, a $5 \%$ de probabilidade. ${ }^{(2)}$ Médias para CE, seguidas de letras iguais, minúsculas nas colunas - dentro de um mesmo processo - e maiúsculas nas linhas, não diferem entre si, pelo teste de Duncan, a $5 \%$ de probabilidade. 
benefícios percebidos no produto e hábitos de consumo têm papel importante na avaliação do consumidor (Shepherd, 1989; Olsen \& Ruiz, 2008). Embora tenha ocorrido diferença na aceitação entre os dois locais, a média foi 7,7 para Londrina e 7,1 para o Rio de Janeiro, as quais podem ser consideradas elevadas. O presente trabalho corrobora os resultados de Gutkoski et al. (2007), que relataram médias entre 7,2 e 7,5 quanto à aceitação global de barras de cereais à base de aveia, com alto teor de fibra alimentar. No entanto, Freitas \& Moretti (2006) desenvolveram barras de cereais à base de proteína de soja texturizada, gérmen de trigo e aveia, enriquecidas com ácido ascórbico e acetato de $\alpha$-tocoferol, em três formulações distintas, e
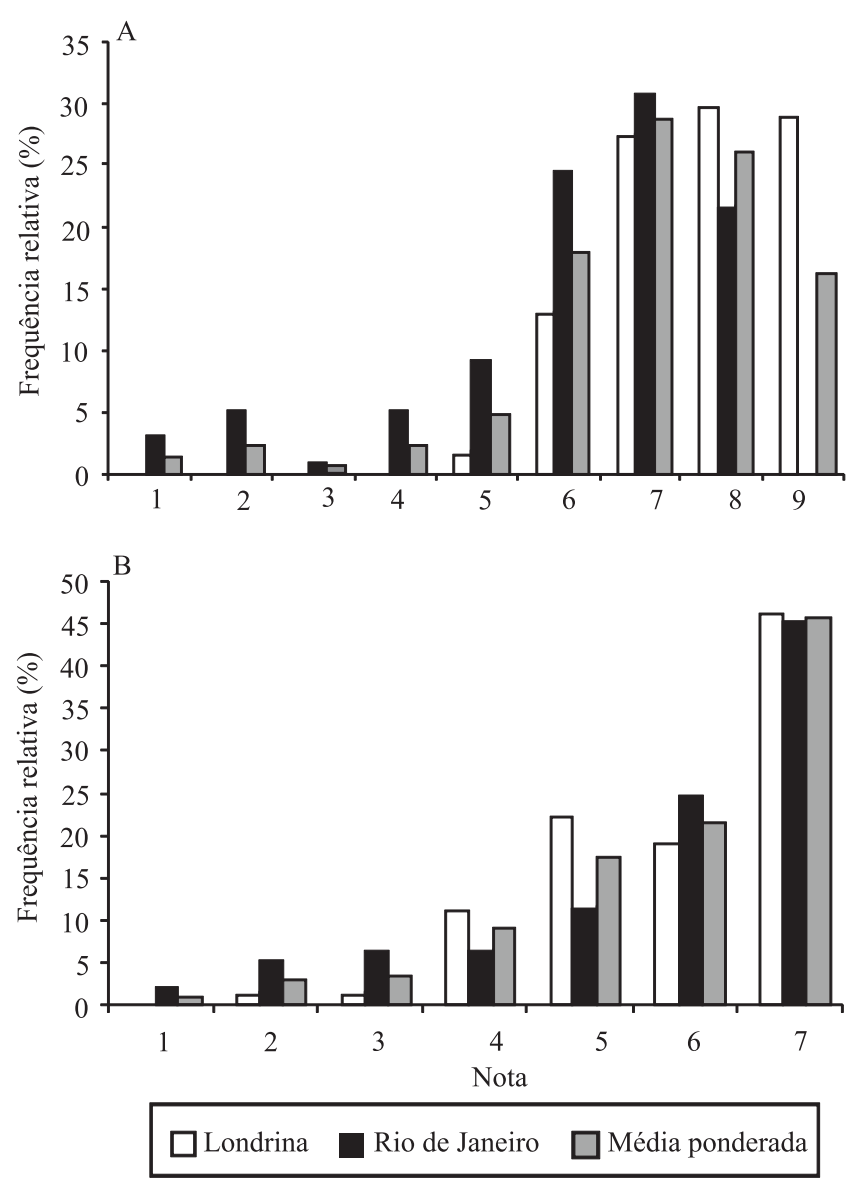

Figura 1. Distribuição da frequência das notas do consumidor para a barra de cereais com pipoca de sorgo: A, aceitação; e B, intenção de compra. A, escala hedônica de 9 pontos, que variou entre "desgostei extremamente" (1) e "gostei extremamente" (9); B, escala estruturada de 7 pontos, que variou de "certamente não compraria" (1) a "certamente compraria" (7). obtiveram médias entre 4,7 e 6,1, na escala hedônica de 9 pontos, em teste sensorial aplicado a uma equipe de 45 consumidores, estudantes da Universidade Estadual de Campinas.

Em Londrina, o produto alcançou maior frequência para as notas 8 ("gostei muito") e 9 ("gostei extremamente"), bem como ausência de rejeição, visto que nenhum consumidor avaliou a barra de cereais com os termos hedônicos "desgostei". Porém, no Rio de Janeiro, ela não foi aceita por $14 \%$ dos consumidores, e a nota 7 ("gostei moderadamente") foi predominante.

A boa aceitação da barra de cereais com pipoca de sorgo pode ser confirmada também pela elevada intenção de compra dos consumidores, pois verificaram-se 88,8 e de $80,6 \%$ de notas acima de 4 , em Londrina e no Rio de Janeiro, respectivamente. Em ambos os locais, a frequência do termo "certamente compraria" foi de $45 \%$.

Estudos subsequentes devem ser realizados com os demais genótipos, que alcançaram desempenho adequado quanto ao rendimento. Alem disso, recomenda-se a realização de outros testes, com número maior de participantes e em outras regiões do país.

\section{Conclusões}

1. O tratamento hidrotérmico dos grãos, antes do pipoqueamento, é benéfico para a redução de piruás e $o$ aumento do rendimento de pipoca.

2. Os genótipos de sorgo BRS 310 e CMSXS 283 apresentam melhor desempenho quanto à produção de pipoca de sorgo.

3. A boa aceitação da barra de cereais com pipoca de sorgo mostra que este cereal tem potencial para uso no desenvolvimento de novos produtos e inserção na alimentação humana no Brasil.

\section{Agradecimentos}

À Empresa Tia Mona, pela produção das barras de cereais utilizadas nos testes de aceitação e de intenção de compra.

\section{Referências}

ACOSTA SANCHEZ, D. White food-type sorghum in direct-expansion extrusion applications. 2003. 132p. Thesis (Master) - Texas A\&M University, College Station. 
COMPANHIA NACIONAL DE ABASTECIMENTO. Acompanhamento da safra brasileira: grãos: safra 2010/2011: décimo primeiro levantamento, agosto/2011. Brasília: CONAB, 2011. 41p.

CRUZ, C.D. Programa GENES: aplicativo computacional em genética e estatística. Viçosa: UFV, 1997. 394p.

DICKO, M.H.; GRUPPEN, H.; TRAORÉ, A.S.; VORAGEN, A.J.; BERKEL, W. Sorghum grain as human food in Africa: relevance of content of starch and amylase activities. African Journal of Biotechnology, v.5, p.384-395, 2006.

DUTCOSKY, S.D.; GROSSMANN, M.V.E.; SILVA, R.S.S.F.; WELSCHA, A.K. Combined sensory optimization of a prebiotic cereal product using multicomponent mixture experiments. Food Chemistry, v.98, p.630-638, 2006.

DYKES, L.; ROONEY, L.W.; WANISKA, R.D.; ROONEY, W.L. Phenolic compounds and antioxidant activity of sorghum grains of varying genotypes. Journal of Agricultural and Food Chemistry, v.53, p.6813-6818, 2005.

FIALHO, E.T.; LIMA, J.A.F. de; OLIVEIRA, V. de; SILVA, H.O. Substituição do milho pelo sorgo sem tanino em rações de leitões: digestibilidade dos nutrientes e desempenho animal. Revista Brasileira de Milho e Sorgo, v.1, p.105-111, 2002.

FREITAS, D.G.C.; MORETTI, R.H. Caracterização e avaliação sensorial de barra de cereais funcional de alto teor protéico e vitamínico. Ciência e Tecnologia de Alimentos, v.26, p.318-324, 2006.

GRANATE, M.J.; CRUZ, C.D.; PACHECO, C.A.P. Predição de ganhos em famílias de meios irmãos do milho-pipoca CMS 431. Ciência e Agrotecnologia, v.26, p.1228-1235, 2002.

GUNDBOUDI, Z.A. Nutritional and processing qualities of pop sorghum cultivars and value addition. 2006. 95p. Thesis (Master) - University of Agricutlural Sciences, Dharwad.

GUTKOSKI, L.C.; BONAMIGO, J.M. de A.; TEIXEIRA, D.M. de F.; PEDÓ, I. Desenvolvimento de barras de cereais à base de aveia com alto teor de fibra alimentar. Ciência e Tecnologia de Alimentos, v.27, p.356-363, 2007.

MATTA, F. de P.; VIANA, J.M.S. Testes de capacidade de expansão em programas de melhoramento de milho pipoca. Scientia Agricola, v.58, p.845-851, 2001.

MÉNDEZ-ALBORES, A.; MARTÍNEZ-BUSTOS, F.; VÉLES-MEDINA, J.J.; MORENO-RAMOS, C.; DEL RÍO-GARCÍA, J.C.; MORENO-MARTÍNEZ, E. Efecto de la adición de ácido cítrico sobre la degradación de las aflatoxinas y las propiedades funcionales de productos extrudidos de sorgo. Interciencia, v.24, p.252-258, 2009.

MENEZES, L.F.G.; SEGABINAZZI, L.R.; BRONDANI, I.L.; RESTlE, J.; ARBOITTE, M.Z.; KUSS, F.; PACHECO, P.S.; ROSA, J.R.P. Silagem de milho e grão de sorgo como suplementos para vacas de descarte terminadas em pastagem cultivada de estação fria. Arquivo Brasileiro de Medicina Veterinária e Zootecnia, v.61, p.182-189, 2009.
MUTISYA, J.; SUN, C.; ROSENQUIST, S.; BAGUMA, Y.; JANSSON, C. Diurnal oscillation of SBE expression in sorghum endosperm. Journal of Plant Physiology, v.166, p.428-434, 2009.

OLSEN, S.O.; RUIZ, S. Adolescents' influence in family meal decision. Appetite, v.51, p.646-653, 2008.

PEREIRA, M.A.; JACOBS JUNIOR, D.R.; PINS, J.J.; RAATZ, S.K.; GROSS, M.D.; SLAVIN, J.L.; SEAQUIST, E.R. Effect of whole grains on insulin sensitivity in overweight hyperinsulinemic adults. American Journal of Clinical Nutrition, v.75, p.848-855, 2002.

PEREIRA, M.M.; OLIVEIRA, A.P. de; BATISTA, P.B.; DIAS, D.L.S.; BRANDÃO, R.K.C.; FARIAS, P.G. O uso do sorgo na alimentação animal: revisão de literatura. Pubvet, v.3, 2009. Disponível em: <http://www.pubvet.com.br/artigos_det. asp?artigo $=587>$. Acesso em: 25 ago. 2011.

PEREZ GONZÁLEZ, A.J. Specialty sorghums in directexpansion extrusion. 2005. 103p. Thesis (Master) - Texas A\&M University, College Station.

QUEIROZ, V.A.V.; BERBERT, P.A.; MOLINA, M.A.B. de; GRAVINA, G. de A.; QUEIROZ, L.R.; DELIZA, R. Desidratação por imersão-impregnação e secagem por convecção de goiaba. Pesquisa Agropecuária Brasileira, v.42, p.1479-1486, 2007.

RAGAEE, S.; ABDEL-AAL, E.S.M. Pasting properties of starch and protein in selected cereals and quality of their food products. Food Chemistry, v.95, p.9-18, 2006.

ROONEY, L.W. Food and nutritional quality of sorghum and millet. Nebraska: INTSORMIL, 2007. (Annual report).

SANTIAGO LUZ, M. de L.; DALPASQUALE, V.A.; SCAPIM, C.A.; LUCCA E BRACCINI, A. de; ROYER, M.R.; MORA, F. Influência da umidade das sementes na capacidade de expansão de três genótipos de milho-pipoca (Zea mays L.). Acta Scientiarum. Agronomy, v.27, p.549-553, 2005.

SCHOBER, T.J.; BEAN, S.R.; BOYLE, D.L. Gluten-free sorghum bread improved by sourdough fermentation: Biochemical, rheological, and microstructural background. Journal of Agricultural and Food Chemistry, v.55, p.5137-5146, 2007.

SHEPHERD, R. Factors influencing food preferences and choice. In: SHEPHERD, R. (Ed.). Handbook of the psychophysiology of human eating. New York: John Wiley, 1989. p.3-24.

TSUNECHIRO, A.; MIURA, M. Relações de preço sorgo/milho nos Estados de São Paulo, Goiás e Rio Grande do Sul, 2001-2009. Informações Econômicas, v.41, p.45-50, 2011.

WANISKA, R.D.; ROONEY, L.W. Structure and chemistry of the sorghum caryopsis. In: SMITH, C.W.; FREDERIKSEN, R.A. (Ed.). Sorghum: origin, history, technology, and production. New York: John Wiley and Sons. 2000. p.649-688.

YENAGI, N.B.; KACHAPUR, M.D.; BHUVANESHWARI, G. Popping quality and proximate composition of pop sorghum cultivars. Research Highlights, v.15, p.119-124, 2005.

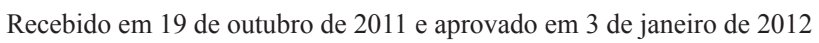

